\title{
Collecting Wind Energy Using Thermal Updrafts
}

\author{
E. Fisher, M. Tubul and I. Shemesh \\ Department of Mechanical Engineering \\ Shamoon College of Engineering \\ Beer-Sheva, Israel \\ E-mail: etanfi@sce.ac.il \\ Phone: +972-8-6475028
}

\begin{abstract}
This study presents an airborne approach to collecting wind energy from thermal updrafts using a glidermounted turbine. Given a single thermal updraft, altitude gain is achieved by climbing the thermal. During the descent from the thermal, wind energy can be collected using a turbine mounted on the glider. In order to minimize drag during the climb, the turbine is designed to be engaged during the descent only.

A proto-type glider with a built-in turbine generator has been constructed. Flight data indicates significant wind energy may be collected using this system. This paper presents the system and flight data analysis and describes the possibilities of flying the glider given a single thermal updraft or within a preferred site of thermal updrafts.
\end{abstract}

Key Words: Airborne Wind Energy, Autonomous Gliders, Autonomous Soaring, Small-scale Wind Turbine.

\section{Introduction}

Airborne wind energy involves production of electricity from wind energy using kites, gliders or lighter-than-air wind turbines [1]. The concept behind airborne wind energy is to create airborne platforms that can be launched beyond the atmospheric boundary layer and gather wind energy from the high-velocity jet streams. This concept is being developed by a small number of companies around the world and has recently been adopted by NASA as a subject for substantial research. Two such systems are: (a) the Makani wing, a tethered glider, designed to fly a circular pattern and collect wind energy via small turbines attached to its body; (b) the Altaeros system, a helium filled balloon with a turbine in its centre. Both systems are designed to be flown at high altitudes and collect wind energy via the tethers. The thermal updraft wind energy collection methods described in this study will be compared to these airborne wind systems.

The initial goal of this study was a glider-mounted wind turbine. The purpose of this system was to gain energy during glides or while climbing in thermals. Initial experiments justified the basic concept of returning energy to the electrical system of the glider; however, little energy may be gained during glides, due to low velocities and relatively short glides. Focus was shifted towards gaining airborne wind energy from thermal updrafts.

Thermal updrafts are a meteorological phenomenon caused by convection in the atmospheric boundary layer [2]. Thermal updrafts are frequently used by birds to gain altitude for energy- efficient flight [3]. Soaring in thermal updrafts is also a skill required by glider pilots for extending flight time and distance. In recent years, soaring has been studied also for the case of autonomous UAVs (Unmanned Airborne Vehicles) [4-6]. Thermal updrafts can be found at heights between several hundred meters and up to a few kilometres. The vertical wind velocity within a thermal can reach above $10 \mathrm{~m} / \mathrm{s}$, and is commonly $2-5 \mathrm{~m} / \mathrm{s}$ [10]. Even though these velocities are considerably low compared to horizontal winds, there are several advantages to the proposed approach. The first is the easy access to the thermal updrafts, due to their relatively low altitude. The second is the mechanical simplicity of the proposed system, involving a glider-mounted turbine. The third advantage relates to the tethered approach of airborne wind energy which can be avoided in the case of thermal updrafts.

This paper will present the various systems necessary for collecting wind energy from thermal updrafts in this manner. These systems include the glider, the wind turbine, the electrical system, and the control system for tracking thermals and keeping the glider within the thermal. The latter control system will be based on recent studies on extending the flight of unmanned aircraft using thermal updrafts [4]. Actual flight experiment data will be used to indicate the amount of power that may be gained by a glider or by a small fleet of gliders given a single thermal updraft.

\section{Thermal Updraft Model}

Thermal updrafts occur due to a convective process in the atmospheric boundary layer (ABL) [2]. As the sun heats the ground, a temperature difference develops between the ground and the air causing a difference in air pressure. Warm air rises upwards creating a widening column of vertical wind. As the air rises it cools down until thermal equilibrium is reached at the top of the ABL. The cooler air is dispersed outwards and downwards, creating a toroid. Figure 1 demonstrates a simplified graphic model of the thermal updraft. The parameter $z_{i}$ represents the convective mixing layer thickness, above which temperature inversion occurs. This layer is commonly occupied by cumulus clouds. In the meteorological modelling of thermal updrafts, two parameters are used to characterize the thermals: The convective mixing layer thickness, $z_{i}$, and the convective velocity scale, $w^{*}$. 
The average vertical velocity at an altitude, $z$, within the thermal can be calculated using:

$$
\bar{w}=w^{*}\left(\frac{z}{z_{i}}\right)^{\frac{1}{3}}\left(1-1.1 \frac{z}{z_{i}}\right)
$$

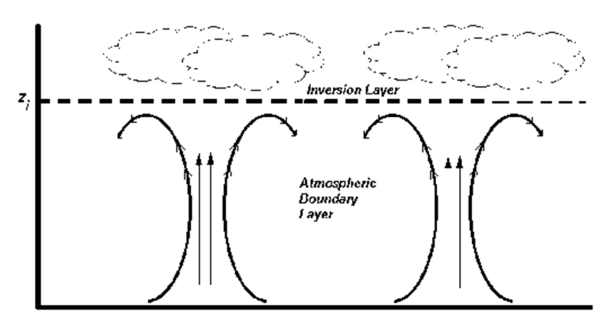

Figure 1: Thermal updrafts in the atmospheric boundary layer

Typical vertical velocity within the thermal is $2-5 \mathrm{~m} / \mathrm{sec}$, while values of above $10 \mathrm{~m} / \mathrm{sec}$ also exist [10]. The diameter of the thermal increases with altitude, and can reach several hundred meters:

$$
D=0.203\left(\frac{z}{z_{i}}\right)^{\frac{1}{3}}\left(1-0.25 \frac{z}{z_{i}}\right) z_{i}
$$

A conservative estimate of the number of thermals encountered within an area of size $\mathrm{X}$ by $\mathrm{Y}$ is [4]:

$$
N=\frac{1.2 X Y}{z_{i} D}
$$

Given a $1 \mathrm{~km}^{2}$ area, and mixing layer thickness of $z_{i}=2 \mathrm{~km}$, yields $\mathrm{N}=2$ thermals per square kilometer. Figure 2 demonstrates this data.

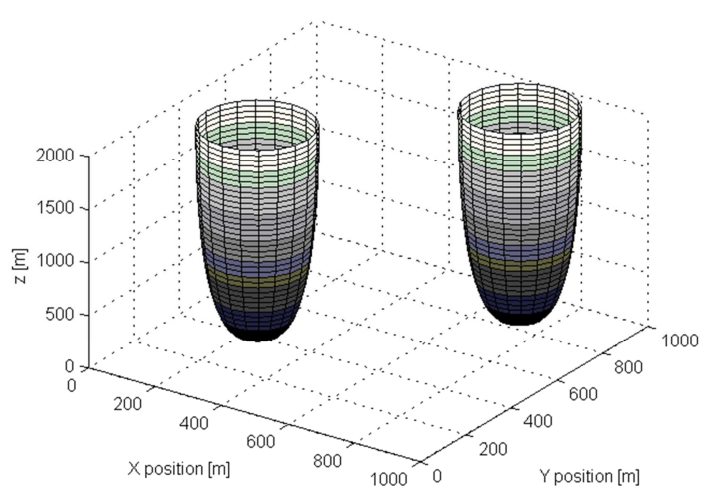

Figure 2: Thermals within $1 \mathrm{~km}^{2}$, for $z_{i}=2000$ meters.

The toroidal curve at the border of the boundary layer (Figure 1) indicates downward vertical winds around the perimeter of the thermal updraft. Data in [4] indicates the downward velocity of these winds is below $1 \mathrm{~m} / \mathrm{sec}$.

\section{3DOF Glider Flight}

A three degree of freedom simplification of the glider flight is assumed, which includes forward and vertical translation ( $x$ and $z$, respectively) and a climb angle, $\gamma$ [7]. The two main forces operating on the glider wing are lift (L) and drag (D). Lift and drag, respectively, express the forces perpendicular and parallel to the air flow along the wing [8]. The ratio between drag and lift also indicates the distance (in meters) that can be glided through given an altitude drop of 1 meter. The resulting accelerations in the inertial frame can be expressed in terms of the air-relative climb angle, $\gamma$ :

$$
\begin{aligned}
& m \ddot{x}=-L \sin \gamma-D \cos \gamma \\
& m \ddot{z}=-L \cos \gamma+D \sin \gamma+m g
\end{aligned}
$$

The standard formulation for lift and drag is:

$$
\begin{aligned}
& L=\frac{1}{2} \rho V^{2} S C_{L} \\
& D=\frac{1}{2} \rho V^{2} S C_{D}
\end{aligned}
$$

where $\mathrm{S}$ is the wing surface, and $C_{L}$ and $C_{D}$ are the lift and drag coefficients, respectively. The total drag coefficient is the sum of the parasitic drag coefficient, and the induced drag coefficient, which can be expressed in terms of the lift coefficient and two other measurable parameters, the aspect ratio, $A R$, and the wing efficiency, $e$ :

$$
C_{D}=C_{D, 0}+\frac{C_{L}^{2}}{\pi A R e}
$$

The relation between the angle of descent and the aircraft velocity, assuming zero wind conditions is given by:

$$
\sin \gamma=\frac{\frac{1}{2} \rho V^{2} S \pi A R e-\sqrt{\left(\frac{1}{2} \rho V^{2} S\right)^{2} \pi A R e\left(\pi A R e+4 C_{D 0}\right)+4 m^{2} g^{2}}}{2 m g}
$$

Figure 3 shows the dependence between angle of descent and the airspeed of the prototype glider. The vertical dotted red line represents the minimal practical airspeed, below which the aircraft would stall. This velocity, calculated using a lift coefficient of $\mathrm{C}_{\mathrm{L}}=1$, is given by:

$$
V_{\text {min }}=\sqrt{\frac{2 m g}{\rho S \sqrt{C_{L, \text { max }}^{2}+\left(C_{D 0}+\frac{C_{L, \max }^{2}}{\pi A R e}\right)}}}
$$

The maximal airspeed that can be reached in a dive is given by:

$$
V_{\max }=\sqrt{\frac{m g}{\frac{1}{2} \rho S C_{D 0}}}
$$

Consider a glider weighing $3.8 \mathrm{~kg}$, with a wing surface of $1 \mathrm{~m}^{2}$, and drag coefficient $C_{D, 0}=0.01$ [9]. The maximal airspeed would be almost $90 \mathrm{~m} / \mathrm{sec}$.

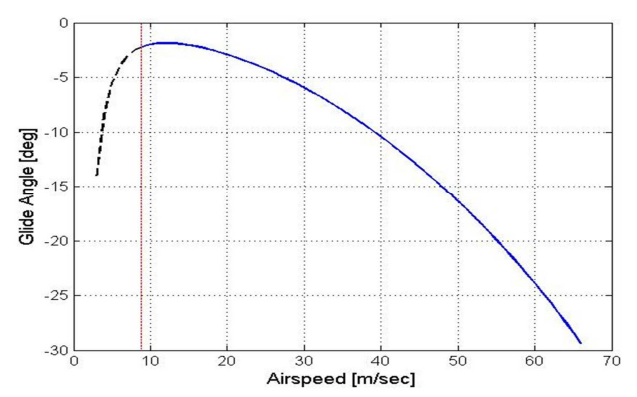

Figure 3: Glider descent angle vs. airspeed 


\section{Thermal Soaring and Gliding}

There are three types of soaring flight: Gust soaring, dynamic soaring and static soaring [3]. Gust soaring occurs when sudden gusts of air provide lift to the airborne bird or aircraft. Dynamic soaring is a technique involving a pattern of downward dives and upwind climbs which can provide a repeated gain of speed traded by a gain in altitude. Dynamic soaring requires a high degree of flight agility and might be considered risky when controlling an autonomous aircraft. This technique was studied for autonomous aircraft recently in [7].

Static soaring, or 'thermal' soaring, utilizes upward moving air (thermal updrafts) to sustain flight, and is the most abundant and widely used method of soaring, by birds and by glider pilots. The procedure of thermal soaring can be divided into four steps: Locating, Entering, Centering and Leaving:

Most of the techniques used by glider pilots to locate thermals rely on visual observation. For example, often a formation of cumulus clouds signals that a thermal is right underneath. If the air inside a thermal contains enough moisture, and the thermal reaches high enough altitude, cumulus clouds form. Another indicator of a thermal is the presence of circling birds. Often, glider pilots visit locations where they encountered thermals repeatedly; these reoccurring thermals are named house thermals. When a glider is close enough to a thermal, the first indication of the thermal's presence is increased sink caused by the entrainment of a thermal. Next, a positive G-force is felt by the glider, caused by the increasing updraft velocity as the glider moves closer to the center of a thermal. Due to the stronger updraft velocity toward the center, the wing closer to the thermal center experiences a stronger lift force than the outer wing. Under these conditions, a glider would roll away by a thermal, if no action is taken by the glider pilot. Glider pilots usually start turning into a thermal either at the strongest updraft location or just right pass that point. After a thermal is located, a glider pilot needs to determine which way to turn in order to enter the thermal properly. This can be determined by the initial roll motion of the glider. If a glider is banked to the right upon entering the thermal, the glider pilot should make a left turn to enter. Once a glider enters the thermal, the pilot should straighten or tighten the turn toward the stronger lift direction. The goal of centering a thermal is to determine the location of the best lift and move the glider into it for the most consistent climb. The set of rules-of-thumb used by glider pilots is:

- As climb improves, flatten the circle

- As climb deteriorates, steepen the circle

- If climb remains constant, keep constant bank

The criterion for leaving a thermal depends on whether the goal is to maximize altitude or shorten cross country flight time. If the goal is to maximize altitude, the glider should stay as long as the climb rate is not negative. In contrast, if the goal is to shorten cross country flight time, the glider should leave as soon as lift is weakened. The former consideration is relevant to the glidermounted turbine methods presented in the following section.

\section{Collecting Wind Energy}

Several approaches may be taken to collecting wind energy from thermal updrafts. The large diameter of the thermal suggests using a large, slow-moving, lightweight turbine similar to the Makani wind turbine [1]. A large turbine would yield significant power even at low vertical velocities. The expected disadvantage of this method is the motion control required for mobilizing and stabilizing the airborne turbine. A relatively indirect approach would be to utilize the thermals for gaining altitude using a conventional lightweight aircraft such as a glider, and use an on-board wind turbine to collect significant wind energy on the descent from the thermal. As stated above, little energy can be gained by the actual flight within a thermal. However, if the descent from the thermal is designed as a controlled dive, the glider can reach high velocities and gain significant power.

Turbine power is calculated using:

$$
P=0.593 \frac{\pi}{8} \rho d^{2} v^{3}
$$

where $\rho$ is the air density, $d$ is the turbine diameter, and $v$ is the incoming wind velocity. Figure 4 shows the theoretical turbine power expected for each of the two systems. Diameter values were chosen based on existing systems. For example, the diameter of the Makani airborne wind turbine is approximately 10 meters. The body diameter of existing model gliders can be more than 0.2 meters, while the prototype glider used in this research has a body diameter of $7 \mathrm{~cm}$ [11]. Table I states the advantages and disadvantages of the proposed methods.
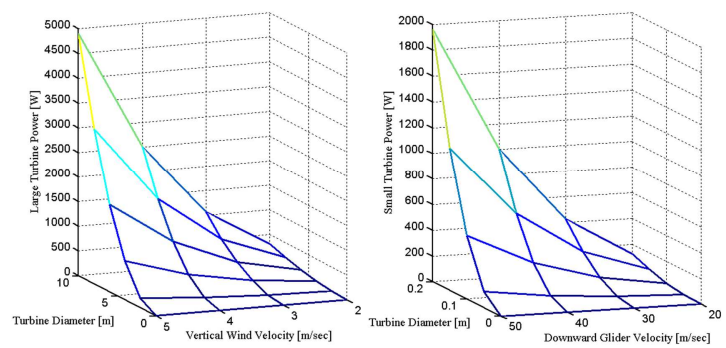

Figure 4: Theoretical power production by large lighter-than-air turbine (left) and glider-mounted turbine (right).

\begin{tabular}{|l|l|l|}
\hline Method & Advantages & Disadvantages \\
\hline $\begin{array}{l}\text { Lighter-than-air } \\
\text { turbine system }\end{array}$ & $\begin{array}{l}\text { High power even at } \\
\text { low vertical velocities } \\
\text { Reduced vertical } \\
\text { instability }\end{array}$ & $\begin{array}{l}\text { Requires specialized design and } \\
\text { manufacturing } \\
\text { Horizontal winds are } \\
\text { significantly stronger }\end{array}$ \\
\hline $\begin{array}{l}\text { Glider-mounted } \\
\text { turbine }\end{array}$ & $\begin{array}{l}\text { Commercially } \\
\text { available platform } \\
\text { High power can be } \\
\text { reached during descent } \\
\text { from thermals }\end{array}$ & $\begin{array}{l}\text { Negligible energy gain during } \\
\text { climb } \\
\text { to the high velocities }\end{array}$ \\
\hline
\end{tabular}

Table I: Advantages / disadvantages of proposed methods

Consider a glider-mounted turbine with a diameter of 0.2 meters travelling between the two thermals appearing in Figure 2. The distance between the two thermals is approximately 651 meters. From Figure 3 , we choose an angle of descent of 30 degrees, yielding an air-speed of approximately $60 \mathrm{~m} / \mathrm{sec}$. Using (12), the power produced by this descent would be approximately $2 \mathrm{~kW}$. In order to collect significant energy, longer descents would be desirable. Given the mixing layer thickness of the example in Figure 2, $z_{i}=2000$ meters, and a descent angle of 30 degrees, a distance of 2310 meters may be travelled, doubling the energy produced by the descent. Assuming a 20 minute climb in the thermal [6], up to 30 cycles may be covered in one day, yielding $0.3 \mathrm{kWh}$. In order to gain the representative amount of $1 \mathrm{kWh}, 3$ or more gliders may be used simultaneously. 


\section{Glider-Mounted Wind Turbine Design}

A radio-controlled glider with a built-in wind turbine and generator was designed and constructed [11]. The glider was constructed using composite materials, which combine a high level of strength together with light-weight, improving energy efficiency.

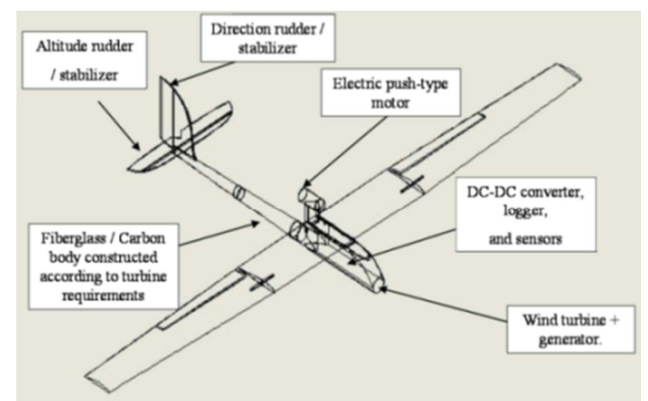

Figure 5: Glider design - top propeller for lift-off and boost, front propeller for wind turbine. Main body components.

Design considerations include three main categories: structural design, design of the wind turbine generator system, and design of an efficient circuit for energizing and recharging the relevant electrical systems.

The glider was designed with two propellers. The driving propeller is located above the plane body. This propeller provides initial lift and provides the extra power required to keep the glider in the air. The wind turbine is located in the front of the glider (Figure 5).

Initially the turbine propeller was placed inside the front end of the glider. Air flow analyses proved that the ideal location in terms of maximal velocity would be external (Figure 6).

The main design parameter affecting drag is the aspect ratio (AR), defined as the ratio between the square of the wing span and the wing surface. A higher aspect ratio decreases the influence of drag induced by air flow. Strength and weight calculations leaded to design of the glider with an AR of 20. The body length and wing span were 1.7 meters and 3.4 meters, respectively. The full weight of the glider, including the electrical components came to approximately $3.8 \mathrm{~kg}$.

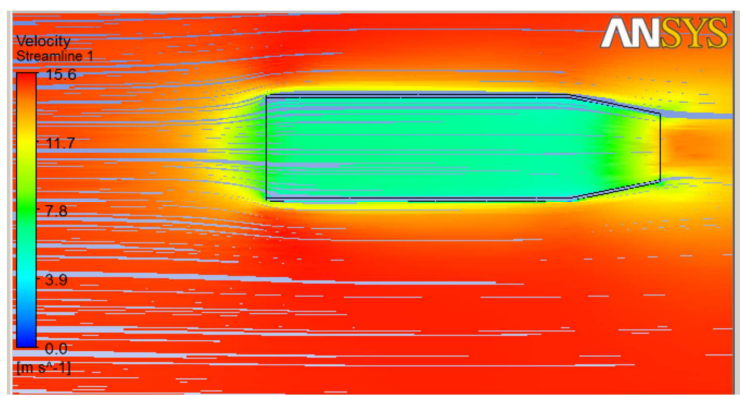

Figure 6: Airflow analysis of glider body.

Initially, the turbine was placed within the glider body. The main consideration was reducing drag during extended flight. Figure 6 shows an air-flow simulation of wind around and through the glider body. Clearly, wind velocity is significantly higher outside the body. Figure 7 shows the prototype glider with the turbine outside the body. Future work will involve other turbine configurations and sizes.

\section{Measured Flight Data}

Several flight tests were performed in order to examine the glider-mounted turbine capabilities and develop the autonomous flight system.

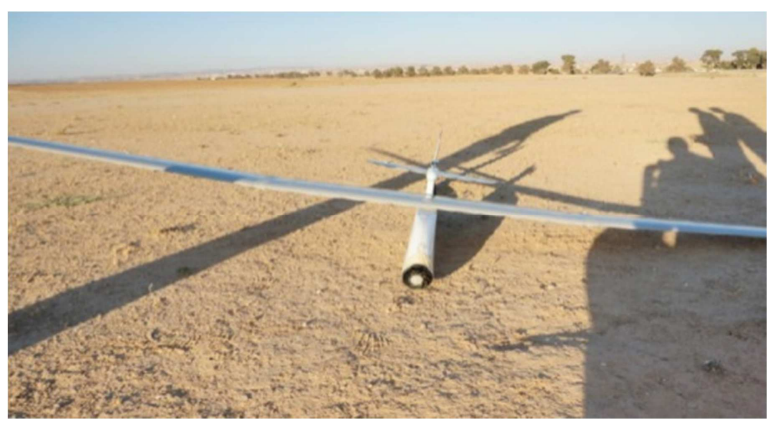

Figure 7: Prototype Glider in the Negev Desert

Figure 8 shows 30 minutes of glider flight in terms of altitude and battery consumption. Active motor usage is indicated by short noisy bursts (yellow), while horizontal curves indicate gliding and soaring. Increase in altitude during glides can be noticed, for example, between minutes 12 and 14. This indicates the glider entered a thermal updraft.

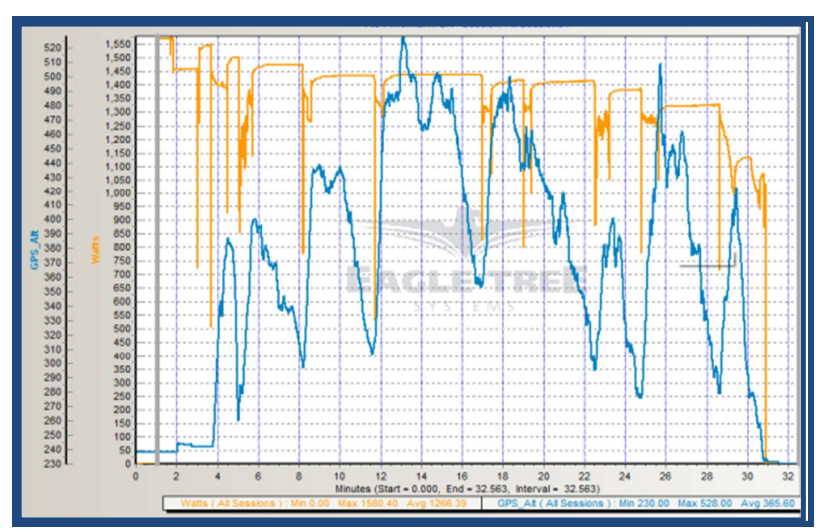

Fig. 8: Battery consumption (in Watts) and altitude vs. time

The power gained by the turbine proved to be lower than the theoretical estimate. Table II shows the theoretical and practical power of the glider turbine and an interpolation of the results to turbines of diameters 0.1 and 0.2 meters.

\begin{tabular}{|c|c|c|c|c|}
\hline $\begin{array}{c}\text { Velocity } \\
(\mathrm{m} / \mathrm{sec})\end{array}$ & $\begin{array}{c}\mathrm{P}=0.07 \\
\mathrm{~d}=0 .\end{array}$ & $\begin{array}{c}\mathrm{P} \\
\mathrm{d}=0.07 \\
\text { (pract.) }\end{array}$ & $\begin{array}{c}\mathrm{P} \\
\mathrm{d}=0.1 \\
\text { (int.) }\end{array}$ & $\begin{array}{c}\mathrm{P} \\
\mathrm{d}=0.2 \\
\text { (int.) }\end{array}$ \\
\hline 15 & 3.85 & 1.2 & 2.5 & 9.8 \\
\hline 30 & 30.8 & 9.6 & 19.6 & 78.4 \\
\hline 45 & 104 & 32.4 & 66 & 264.5 \\
\hline 60 & 246.5 & 67.2 & 137 & 548.6 \\
\hline
\end{tabular}

Table II: Theoretical and practical energy produced using glider-mounted wind turbine

The complete autonomous system is designed using the ardupilot flight controller and Mission Planner software for the flight plan. Figure 9 shows a screen shot of data from an actual flight demonstrating vertical climb (vertical velocity $=4.74$ $\mathrm{m} / \mathrm{sec}$ ). The large right-hand window displays the flight GPS data on the corresponding Google Maps data. 


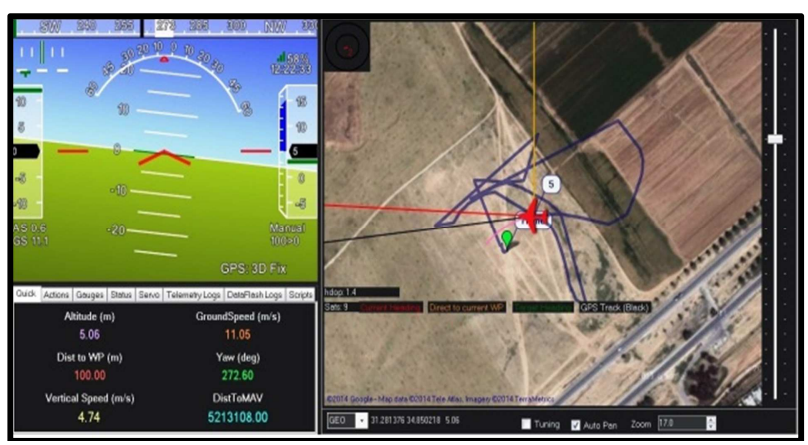

Figure 9: Test flight using Mission Planner autonomous / remote glider control interface

\section{Conclusion}

A system for harvesting wind energy from thermal updrafts is suggested. The system may be based around a fleet of simple gliders incorporating small wind turbines. The thermal updraft provides lift and potential energy which can be converted to wind energy during rapid descent from the thermals. Another possibility for harvesting wind energy from thermal updrafts is a large lighter-than-air turbine which can be maneuvered directly above thermals to produce wind energy.

Several stages of the glider-based system were presented including a prototype glider and the required infrastructure. The authors hope to reach a working system incorporating several gliders for producing significant energy in off-grid locations.

\section{References}

1. Vance, E., "High Hopes," Nature, Vol. 460, July 2009.

2. Lenschow, D. H. and Stephens, P. L.,"The role of thermals in the convective boundary layer," Boundary-Layer Meteorology, vol.19, pp. 509-532, December 1980.

3. Li, Z. M., "Modeling and Simulation of Autonomous Thermal Soaring with Horizon Simulation Framework," M.Sc. Thesis, California Polytechnic State University, 2010.

4. Allen, M. J., "Autonomous soaring for improved endurance of a small uninhabited air vehicle," In Proceedings of AIAA Aerospace Sciences Meeting and Exhibit, NASA Dryden Flight Research Center, 2005.

5. Allen, M. J., "Updraft model for development of autonomous soaring uninhabited air vehicles," In Proceedings of AIAA Aerospace Sciences Meeting and Exhibit, 2006.

6. Allen, M. J., "Guidance and Control of an Autonomous Soaring UAV," NASA / TM-2007-214611, February 2007.

7. Lawrance, N. R. J., "Autonomous Soaring Flight for Unmanned Aerial Vehicles," Ph.D. Thesis, University of Sidney, Australia, 2011.

8. Frati, S., "The Glider (L'Aliante)," Politecnico de Milano, 1946, translated, A. Scott et. al., circa 2008.

9. Sadraey, M., "Aircraft Design: A Systems Engineering Approach," Wiley Publications, 2012.

10. Childress, C. E., "An Empirical Model of Thermal Updrafts Using Data Obtained From a Manned Glider," M.Sc. Thesis, University of Tennessee, 2010.

11. M. Tubul, S. Stamker and E. Fisher, "Design and Construction of Radio-Controlled Glider with Renewable Energy Capabilities," ICREPQ '12, Santiago De Compostela, Spain, March, 2012. 